\title{
Miscellany
}

\section{The Lucy Faithfull Travel Scholarship Fund}

Baroness Faithfull, who died in 1996, devoted her life to the care of deprived or disturbed children. A travel scholarship in her name of $£ 2500$, is to be awarded in June 1999. Applications are invited from senior trainees, or consultants within two years of appointment, in the specialities of child psychiatry or community child health who wish to broaden their experience or conduct research in other centres in the UK or abroad. The closing date for applications is 20 March 1999. Further information: $\mathrm{Mr} \mathrm{M}$. H. Gough, PO Box 229, Kidlington, OX5 3YT.

\section{MmND Millennium Awards}

In the run-up to the year 2000 , The Millennium Commission is making funds available for the MIND Millennium Awards. The scheme currently has over 140 award winners developing different ideas and projects to help break down stigma and prejudice that surrounds mental health. However, it remains under-subscribed, and applications are invited from individuals and small groups to help with projects relevant to mental health which offer a benefit to the local community, and raise the profile of mental health. Particularly welcome are one-off events and projects taking place in 1999, which need funding of around £1000-£5000. Further information: The Millennium Awards Team MIND, 15-19 Broadway, London E15 4BQ (Telephone: 01815192122 extension 285).

\section{UK Register of Expert Witnesses}

J. S. Publications are preparing the 12th edition of the UK Register of Expert Witnesses, a 'live' database of expert witnesses and expertise. With over 3000 experts currently listed, the Register is primarily used by solicitors and barristers but may also be purchased by insurers and corporate lawyers. Individuals from any discipline can be listed provided they have been recommended by at least one solicitor who has instructed them to write a report or give expert evidence in court. Inclusion on the Web Register is also offered. Further information: Kate Porter, J. S. Publications, PO Box 505, Newmarket, Suffolk CB8 7TF (Telephone: 01638561 590, Fax: 01638560 294, e-mail: Ukrew@jspubs.com).

\section{New publications}

The Clinical Effectiveness project Team at the Royal College of Psychiatrists' Research Unit has produced Improving the Care of Elderly People with Mental Health Problems: Clinical Audit Project Examples. This book focuses on mental health services for elderly people and contains 43 'live' examples of clinical audit projects that have been undertaken in services throughout Britain. It also includes notes and advice from the clinicians who undertook the projects, examples of standards used, clinical audit resources and relevant references. Further information: Kirsty MacLean Steel (Telephone: 01712352351 extension 273).

The Health and Safety Executive has published a report entitled From Accidents to Assaults - How Organisational Responses to Traumatic Incidents Can Prevent Post-Traumatic Stress Disorder in the Workplace. The report explores what can be done to stop the symptoms that can result from traumatic incidents developing into more serious illness, and looks at the effectiveness of counselling in preventing post-traumatic stress disorder. Priced at £32.50, copies are available from (ref. CRR 195/98, ISBN 0-7176-1631-2): HSE Books, PO Box 1999, Sudbury, Suffolk, CO10 6FS (Telephone: 01787881 165, Fax: 01787313 995).

The National Depression Campaign has produced new materials on depression and employment based on the findings of their three National Employment Voice Conferences. Wanting to Work is a leaflet containing recommendations for people wanting to return to work after a depressive illness, and Understanding Depression for Employers and Managers is a leaflet that looks at ways of recognising and managing depression, preventative measures and frequent concerns. An Employers Display Pack on Depression including cartoon posters for display in the work place is also available. Copies can be obtained by sending a stamped addressed envelope to: National Depression Campaign, 35 Westminster Bridge Road, London SE1 7JB. Order forms for the display pack can be obtained by calling the following telephone number: 0171 2073293.

Caring for Ethnic Minority Elders, by Yasmin Alibhai-Brown, is a new title from Age Concern Books. Extensively researched over three years, 